J. Clin. Chem. Clin. Biochem.

Vol. 20, 1982, pp. 713-721

\title{
Topographic and Age-Dependent Distribution of the Glycosaminoglycans in Human Aorta
}

\author{
By H. W. Stuhlsatz, H. Löffler, V. Mohanaradhakrishnan, S. Cosma and H. Greiling \\ Abteilung Klinische Chemie und Pathobiochemie der Med. Fakultät an der RWTH Aachen
}

(Received February 5/June 6, 1982)

Summary: Keratan sulfate was found to be present in all segments of human aortae of different age.

The total glycosaminoglycan content decreases from 18.2 in the 2 nd to $14.2 \mu \mathrm{mol}$ hexosamine per $\mathrm{g}$ dry weight in the 8th decade. This decrease becomes more pronounced, if the inorganic material (calcium phosphate), the proportion of which increases from $10 \mathrm{~g} / \mathrm{kg}$ (2nd) to $140 \mathrm{~g} / \mathrm{kg}(8 \mathrm{th}$ ), is included in the dry weights; the total glycosaminoglycan content, then decreases from 18.0 in the 2 nd to $12.4 \mu \mathrm{mol}$ per $\mathrm{g}$ dry weight in the 8 th decade:

The glycosaminoglycans in human aortae between the 2nd and the 8th decade of age consist chiefly of chondroitin 4-sulfate (20-30\%), chondroitin 6-sulfate (20-29\%) and heparan sulfate (18-27\%), followed by dermatan sulfate $(13-17 \%)$, hyaluronate $(5-15 \%)$, keratan sulfate $(4-8 \%)$ and chondroitin $(1-3 \%)$.

The concentrations of chondroitin 6-sulfate and heparan sulfate decrease from the 2 nd to the 8 th decade, whereas the concentration and relative proportion of keratan sulfate increase especially from the 6th to the 8th decade.

With regard to the longitudinal distributions of the glycosaminoglycans in human aortae the 4th and the 8th decade of age were studied. The total glycosaminoglycan concentration of the younger group exhibits an increase from proximal to distal regions, whereas in the older group the glycosaminoglycan concentration remains nearly constant in all segments, being higher in the aortic arch and lower in the two distal regions than in the corresponding regions of younger aortae.

In the region of the aortic arch the concentration and the relative proportion of hyaluronate, dermatan sulfate and chondroitin 4-sulfat decrease on ageing, whereas those of heparan sulfate, keratan sulfate and chondroitin 6-sulfate increase. In the middle region of human aortae only keratan sulfate and chondroitin 4-sulfate increase with age. In the region of the bifurcatio, where the highest deposition of inorganic material has been found, contents and relative proportions of hyaluronate, keratan sulfate and dermatan sulfate increase during ageing, whereas those of heparan sulfate and the chondroitin sulfates, especially chondroitin 6-sulfate, decrease.

\section{Topographische und altersäbhängige Verteilung der Glykosaminoglykane in der Aorta des Menschen}

Zusammenfassung: Keratānsulfat wurde in allen Abschnitten der Aorta des Menschen gefunden.

Der Gesamtgehalt der Glykosaminoglykane nimmt von $18,2 \mu \mathrm{mol} / \mathrm{g}$ Trockengewicht in der 2 . Altersdekade auf 14,2 in der 8. ab. Diese Abnahme ist noch stärker ausgeprägt, wenn die mineralischen Rückstände (Calciumphosphat), deren Anteil von $10 \mathrm{~g} / \mathrm{kg}$ im 2. auf $140 \mathrm{~g} / \mathrm{kg}$ im 8 . Jahrzehnt ansteigt, in das Trockengewicht einbezogen werden; der Glykosaminoglykan-Gesamtgehalt sinkt dann von 18,0 in der 2. auf $12,4 \mu \mathrm{mol} / \mathrm{g}$ Trockengewicht in der 8 . Lebensdekade.

Die Hauptanteile der Aorta-Glykosaminoglykane zwischen dem 2. und 8. Lebensjahrzehnt bilden Chondroitin-4-sulfat (20-30\%), Chondroitin-6-sulfat (20-29\%) und Heparansulfat (18-27\%), gefolgt von Dermatansulfat (13-17\%), Hyaluronat $(5-15 \%)$, Keratansulfat $(4-8 \%)$ und Chondroitin $(1-3 \%)$.

Die Konzentrationen von Chondroitin-6-sulfat und Heparansulfat nehmen von der 2. zur 8. Dekade ab, wogegen Keratansulfatgehalt und -anteil besonders vom 6. zum 8. Lebensjahrzehnt zunehmen.

Hinsichtlich des longitudinalen Verteilungsmusters der Glykosaminoglykane in der humanen Aorta wurden das 4. und 8. Lebensjahrzehnt untersucht. Hiernach zeigt die jüngere Gruppe einen Anstieg der Glykosaminoglykan-Gesamtkonzentration von proximal nach distal, die der älteren Gruppe hingegen bleibt in allen Segmenten nahezu konstant, wobei der Glykosaminoglykangehalt im Aortenbogen-Abschnitt höher, in den beiden distalen Segmenten niedriger als in den entsprechenden Abschnitten der jüngeren Aorten ist. 
Im Aortenbogen nehmen mit zunehmendem Alter Konzentration und relativer Anteil von Hyaluronat, Dermatansulfat und Chondroitin-4-sulfat ab, von Heparansulfat, Keratansulfat und Chondroitin-6-sulfat jedoch zu. Im mittleren Aortenabschnitt ist nur eine Zunahme des Keratansulfat- und Chondroitin-4-sulfat-Gehaltes festzustellen. Im Bifurcatio-Abschnitt, wo der höchste Gehalt an mineralischen Ablagerungen gefunden wurde, steigen die Gehalte und relativen Anteile von Hyaluronat, Keratansulfat und Dermatansulfat an, während diejenigen von Heparansulfat und den Chondroitinsulfaten, insbesondere von Chondroitin-6-sulfat, abnehmen.

\section{Introduction}

The mean thickness of the blood vessel wall is doubled from the 20th to the 70th year of age. An increase in the collagen content is predominantly responsible for this change, in addition to changes in the ground substance. Furthermore, the mean thickness of collagen fibrils in the human aorta increases with ageing, as does the degree of crosslinking of collagen and elastin (1), whereas cell density and activity of the enzymes in energy metabolism decrease with age. Several groups have determined the change in glycosaminoglycan content in human aortic tissue with ageing. Kaplan \& Meyer (2) as well as Böttcher \& Klynstra (3) were not able to establish a significant age-dependent alteration of the total glycosaminoglycan content. It has been shown that the proportion of hyaluronate to chondroitin sulfates decreases with age $(2,4,5)$. Buddecke $(6)$, however, found an increase of hexosamine, especially of glucosamine. According to Clausen (7) the uronic acid content of the aorta decreases with age, whereas Krüger \& Teller (8) established an increase of the uronic acid content. Recently Toledo \& Mourao (9) showed that the chondroitin 6-/4-sulfate ratio in the intima + media layers of human aortae increases with age.

On account of these contradictory results we took up again the question of age-dependent changes of the aortic glycosaminoglycans using a specially adapted method that prevents any loss of glycosaminoglycan during the isolation procedure.

This was especially important with regard to keratan sulfate, the existence of which in human aortic tissue had been postulated but not clearly identified by Buddecke (6). Some years ago we isolated and characterized keratan sulfate from human aorta $(10-12)$. Since keratan sulfate could play an important role in the pathogenesis of atherosclerosis, it became another task of the present study to investigate the distribution of keratan sulfate in human aortic segments of different age.

The results of Toledo \& Mourao concerning the distribution of glycosaminoglycans in the different aortic wall layers demonstrate that the glycosaminoglycan concentration decreases continuously from the intima to the adventitia (9). In the same direction they found an increase in the proportion of dermatan sulfate, but an decrease in that of heparan sulfate. Murata et al. (13), however, reported an increase of dermatan sulfate and heparan sulfate. Little is known about the age-depend- ent glycosaminoglycan distribution pattern along the human aorta. Manley \& Hawsksworth (14) published an observation concerning the distribution of hyaluronate, heparan sulfate and chondroitin sulfate in the ascending, the thoracic and abdominal aorta of a man of 29. Recently, Montani et al. (15-17) studied the distribution of glycosaminoglycans as a function of age and of the number of atherosclerotic lesions in the human aortic arch and abdominal aorta, but the methods applied by these authors did not seem suitable for producing reliable results. Thus, it became the third topic of the present study to determine the topographic glycosaminoglycan distribution along human aortae of different ages.

\section{Materials and Methods}

Chemicals

Cryst. papain was obtained from Sigma, München; ABC-lyasase (EC 4.2.2.4), AC-lyase (EC 4.2.2.5), chondro-4-(EC 3.1.6.9) and chondro-6-sulfatase (EC 3.1.6.10) were from Miles, Frankfurt; galactose dehydrogenase was purchased from Boehringer, Mannheim. Dowex $1 \times 2$ (200-400 mesh) was from Serva, Heidelberg; Bio-Gel P-2 was obtained from Bio-Rad Laboratories, München; Sephadex G-100 was purchased from Pharmacia, Frankfurt. The cellulose sheets $(20 \times 20 \mathrm{~cm})$ used were from Merck, Darmstadt. The standard glycosấminoglycans used were highly purified and characteriżed préparations from human liver and pig skin (dermatan sulfate), bovine tracheal cartilage (chondroitin 4- and 6-sulfate, separated on a cellulose-column in calcium acetate/ethanol at different ethanol concentrations), from bovine vitreous humour (hyaluronate), bovine cornea and tracheal cartilage (keratạn sulfate), from human and bovine liver (heparan sulfate).

All other chemicals ušed were of p.a. quality standạrd.

\section{Human aortae}

The aortae were obtained immediately after section within 12 to 20 hours post mortem. None of the patients suffered from diabetes mellitus or more than age-related hypertonus, hypothyreosis, disordered lipid metabolism, or, despite atherosclerotic lesions, from an aortic disorder, e.g. mesaortitis syphilitica.

Aortae from 4 age-groups were collected: one aorta from the second decade of age (13 years), 5 aortae each from the 4th decade ( $31-38$ years), 6 th decade $(52-59$ years) and 8 th decade (69-76 years). After removal of the adventitia, the aortae of the 4th and 8th decade were divided intọ three segments,

segment A corresponding to the aortic arch and the aorta descendens to the region a little above the truncus coeliacus, segment B from there to just below the arteria mesenterica inferior, and

segment $\mathrm{C}$ from this region to the bifurcatio aortae including the proximal $3-5 \mathrm{~cm}$ of the arteriae iliacae communes. 
From each segment a 3-5 mm segment was taken for histological examination. All aortae were kept at $4^{\circ} \mathrm{C}$ in absolute ethanol until processed.

The aortae were cut into small pieces $(2-3 \mathrm{~mm})$ and then powdered in an electric mill under liquid nitrogen. For lipid extraction the powder was suspended in acetone (10 g powder in $150 \mathrm{ml}$ acetone), stirred for 12 hours, filtered, washed three-times with acetone, dried at $50^{\circ} \mathrm{C}$ and the dry weight determined.

Isolation and separation of the aortic glycosaminoglycans Aliquots of the powdered tissue from total aortae of all age groups as well as from the segments A, B and C of the fourth and eighth decade of age were digested twice with cryst. papain $\left(0.5 \mathrm{mg} / \mathrm{g}\right.$ dry tissue) at $60^{\circ} \mathrm{C}$ for a total of 72 hours in sodium acetate buffer $\mathrm{pH} 6.8(0.10 \mathrm{~mol} / 1$ sodium acetate, $0.005 \mathrm{~mol} / \mathrm{l}$ ethylenediaminetetraacetate, disodium salt, $0.005 \mathrm{~mol} / 1$ cysteine hydrochloride) at a concentration of $3 \mathrm{~g}$ tissue in $100 \mathrm{ml}$ buffer. After 36 hours another portion of papain and cysteine hydrochloride was added. The mixture was filtered, the crystalline residue washed three-times with acetone, dried and weighed. By infrared spectroscopy these residues were shown to be primarily calcium phosphates. All values given in this study are related to the dried tissues minus the inorganic residues. The filtered proteolysate was acidified to $\mathrm{pH} 1.3$ with $\mathrm{HCl}$, the precipitates formed were separated by centrifugation and discarded, the supernatant neutralized with $\mathrm{NaOH}$ and concentrated to one tenth of volume.

Desalting was performed on Bio-Gel P-2 columns $(2 \times 90 \mathrm{~cm})$ equilibrated and eluted with ethanol/water (volumes, $100+$ $900 \mathrm{ml}$ ) and $5 \mathrm{ml}$ portions were collected. The glycosaminoglycans were monitored by uronic acid determinations and the salts by conductivity measurements. The glycosaminoglycancontaining portions were pooled and concentrated to $10 \mathrm{ml}$.

For the evaluation of optimal separation conditions of the aortic gly cosaminogly.cans by chromatography on Dowex $1 \times 2$, an aliquot of the desalted glycosaminoglycan mixture from aortae of the sixth decade was loaded onto a Dowex $1 \times 2$ column $(2 \times 20 \mathrm{~cm})$ equilibrated with $0.15 \mathrm{~mol} / 1 \mathrm{NaCl}$. Elution was performed with 3 bed-volumes each of stepwise increasing $\mathrm{NaCl}$ concentrations: $0.15-0.25-0.50-0.75-1.0-1.25-1.5-$ 1.75-2.0-3.0 mol/1. Each fraction was concentrated, desalted by gel filtration on Bio Gel P-2, and analysed for the glycosaminoglycan types.

As a result of the foregoing chromatography on Dowex $1 \times 2$ the separation procedure could be shortened to an elution program with only four concentrations of $\mathrm{NaCl}$ :

\subsection{5 (fraction I)}

\section{5 (fraction II)}

\section{5 (fraction III)}

\section{0 mol/1 (fraction IV).}

All gly cosaminoglycan mixtures from total aortae or from segments A, B and C of different age are fractionated on Dowex $1 \times 2$ columns $(2 \times 20 \mathrm{~cm})$ by elution with thiree bed-volumes each of these four NaCl-solutions. The desalted fractions II, III and IV were then analyzed for their gly cosaminoglycan types and constituents. To get further information about the composition of the aortic keratan sulfate fractions an aliquot of fraction IV $(3.0 \mathrm{~mol} / \mathrm{l} \mathrm{NaCl})$ of the eighth decade $(69-76$ years) was chromatographed on a Sephadex G-100 column (1.5 X $150 \mathrm{~cm}$ ) eluted with $100 \mathrm{ml} / \mathrm{l}$ ethanol. The elution profile is shown in figure 2. Four subfractions IV-1, IV-2, IV-3 and IV:4 were obtained, the data of the main constituents of which are listed in table 1 .

Thin-layer chromatography of the aortic glycosaminoglycans

TLC on cellulose sheets $(20 \times 20 \mathrm{~cm})$ of the calcium salts of the gly cosaminogly cans were performed according to Humbel \& Chamoles (18). This technique was also extended to the barium salts of the glycosaminoglycan mixtures. The spots (not stained) of aortic keratan sulfate and heparan sulfate positions from every age group were scraped off and the cellulose powder extracted with water $(3 \times 0.5 \mathrm{ml})$. After evaporation to dryness, re-sólubilization with water and hydrolysis in $3 \mathrm{~mol} / 1 \mathrm{HCl}$ at $105^{\circ} \mathrm{C}$ for 15 hours, glucosamine was determined in the amino acid analyzer.

Analysis of the aortic glycosaminoglycan types

Hyaluronate was determined by degradation with hyaluronate lyase (EC 4.2.2.1) according to Greiling (19) with the following modification: after incubation 3 volumes of sodium acetatesaturated ethanol were added, the mixture was centrifuged, the supernatant evaporated to dryness, re-solubilized in $1 \mathrm{ml} \mathrm{H}_{2} \mathrm{O}$, hydrolysed in $3 \mathrm{~mol} / 1 \mathrm{HCl}$ at $105^{\circ} \mathrm{C}$ for 15 hours and the glucosamine content determined in the amino acid analyzer.

Chondroitin (= very low sulfated chondroitin sulfate) was determined as galactosamine in fraction II $(0.5 \mathrm{~mol} / 1 \mathrm{NaCl})$ after chondroitin $\mathrm{ABC}$-lyase treatment (20) followed by precipitation with 3 volumes of sodium ace tate-saturated ethanol, centrifugation, evaporation of the supernatant to dryness, re-solubilization in water, hydrolysis in $3 \mathrm{~mol} / 1 \mathrm{HCl}$ at $105^{\circ} \mathrm{C}$ for 15 hours and galactosamine determination in the amino acid analyzer.

To ascertain the chondroitin 4-sulfate, chondroitin 6-sulfate and dermatan sulfate contents, degradation with chondroitin AC-lyase (EC 4.2.2.5), chondroitin ABC-lyase (EC 4.2.2.4) in combination with chondro-4- and chondro-6-sulfatase (EC 3.1.6.9 and EC 3.1.6.10, resp.) was used (20).

Heparan sulfate in fractions II, III and IV was estimated after degradation with nitrous acid (21) followed by precipitation with 3 volumes of sodium acetate-saturated ethanol, centrifugation, re-solubilization of the precipitate, hydrolysis in $3 \mathrm{~mol} / 1$ $\mathrm{HCl}$ at $105^{\circ} \mathrm{C}$ for 15 hours and glucosamine determination by means of an amino acid analyzer. An aliquot of the re-solubilized precipitate was subjected to TLC on cellulose sheets in the barium acetate system. Spots (not stained) remaining at the start and containing dermatan sulfate and heparan sulfate were scraped off, the cellulose powder extracted with water $(3 \times$ $0.5 \mathrm{ml}$ ) and the extract estimated for glucosamine after hydrolysis in $3 \mathrm{~mol} / \mathrm{l} \mathrm{HCl}$. The difference in glucosamine values before and after degradation with $\mathrm{HNO}_{2}$ plus the glucosamine value remaining at the start in TLC was taken as the value for heparan sulfate.

\section{Analy ses of the aortic gly cosaminogly can constituents}

Uronic acid was determined using the carbazole reaction of Dische (22) as modified by Bitter \& Muir (23), but in a fully mechanized version (24) which permits 40 determinations per hour down to a concentration of $10 \mu \mathrm{mol} / 1$. The galactose content was measured enzymatically with galactose dehydrogenase (25) after hydrolysis in $1 \mathrm{~mol} / 1 \mathrm{HCl}$ for 3 hours at $105^{\circ} \mathrm{C}$. Sulfate was determined turbidimetrically as $\mathrm{BaSO}_{4}(26)$ after hydrolysis in $1 \mathrm{~mol} / 1 \mathrm{HCl}$ for 3 hours at $105^{\circ} \mathrm{C}$. Glucosamine and galactosamine, together with amino acids, were determined af ter hydrolysis for 15 hours in $3 \mathrm{~mol} / 1 \mathrm{HCl}$ at $105^{\circ} \mathrm{C}$ using an amino acid analyzer (27). The elution program of the analyzer was modified to allow the determination of glucosamine and galactosamine (positioned between the amino acids phenylalanine and lysine) and the other amino acids in less than $2^{1 / 2}$ hours down to the $100 \mathrm{pmol}$ range. Quantitative iduronicglucuronic acid separation was performed according to 1.c. (40).

\section{Results}

\section{Isolation and characterization of keratan sulfate in human aortic segments of different age}

In preliminary experiments to differentiate the glycosaminoglycans of human aortae from different age groups the presence of glucosamine-containing glycosaminoglycans was shown in fractions eluted from Dowex $1 \times 2$ columns with $3 \mathrm{~mol} / 1 \mathrm{NaCl}$ solution. As heparan sulfates, even those with high degrees of sulfation, are eluted 
from Dowex $1 \times 2$ with lower $\mathrm{NaCl}$ concentrations (at most $1.75 \mathrm{~mol} / \mathrm{l}$ ), the suspicion became strong that the glucosamine content in the $3 \mathrm{~mol} / \mathrm{l} \mathrm{NaCl}$-fraction might be attributable to keratan sulfate.

To evaluate the optimal conditions for separating heparan sulfates from keratan sulfate by Dowex $1 \times 2$ chromatography, aortic glycosaminoglycans of the sixth decade of age were separated into several fractions by elution with stepwise increasing concentrations of $\mathrm{NaCl}$. Analyses of the fractions were performed by TLC on cellulose sheets as the calcium and as the barium salts, by glucosamine and galactosamine determinations, by enzymic methods using hyaluronate lyase, chondroitin AC-lyase and $\mathrm{ABC}$-lyase, and by degradation with $\mathrm{HNO}_{2}$.

Hyaluronate could be detected only in the fraction eluted with $0.5 \mathrm{~mol} / 1 \mathrm{NaCl}$ together with small amounts of very low sulfated chondroitin sulfates (chondroitin). The chondroitin sulfates and dermatan sulfate were found in all fractions eluted with $0.75 \mathrm{~mol} / 1 \mathrm{NaCl}$ up to $3.0 \mathrm{~mol} / 1$ (fig. 1 , results of the fraction $0.75 \mathrm{~mol} / 1 \mathrm{NaCl}$ not shown), whereas heparan sulfate and keratan sulfate exhibited a relatively clear-cut separation from each other. The overlapping fractions of these two glycosaminoglycans were eluted with 1.5 and $1.75 \mathrm{~mol} / 1 \mathrm{NaCl}$ (fig. 1), but the heparan sulfate in fraction $1.75 \mathrm{~mol} / 1$ $\mathrm{NaCl}$ represented less than $5 \%$ of total heparan sulfate, and the keratan sulfate in fraction $1.5 \mathrm{~mol} / 1 \mathrm{NaCl}$ made up less than $10 \%$ of total keratan sulfate. Since more than $90 \%$ of total keratan sulfate was found in the fractions eluted with $1.75,2.0$ and $3.0 \mathrm{~mol} / 1 \mathrm{NaCl}$ and more than $95 \%$ of total heparan sulfate in the fractions eluted with $1.0,1.25$ and $1.5 \mathrm{~mol} / 1 \mathrm{NaCl}$, the elution program for estimating the glycosaminoglycan distribution along the aortae of different age-groups was simplified by choosing only four concentrations of $\mathrm{NaCl}$ : 0.15 (fraction I), 0.5 (fraction II), 1.5 (fraction III) and $3.0 \mathrm{~mol} / 1$ (fraction IV), whereby the glucosamine in fraction II $(0.5 \mathrm{~mol} / 1 \mathrm{NaCl})$ represented hyaluronate, that in fraction III ( $1.5 \mathrm{~mol} / 1 \mathrm{NaCl})$ heparan sulfate, and that in fraction IV (3.0 mol/1 NaCl) keratan súffate.

All fractions, II, III and IV, were monitored by TLC in calcium and barium acetate systems before and after degradation with chondroitin ABC-lyase. TLC of the glycosaminoglycans in both systems has the advantage of mutual control, since in the barium acetate system heparan sulfate and dermatan sulfate remain at the origin, whereas in the calcium acetate system this is true only for dermatan sulfate.

Though the results of TLC proved the presence of keratan sulfate in all human aortic segments of different age, an additional attempt was made to get more information about the constituents of the keratan sulfate fractions. For this purpose, an aliquot of the fraction IV (3.0 mol/1 $\mathrm{NaCl})$ of the eight decade (69-76 years) was fractionated further by gel chromatography on Sephadex G-100 (fig. 2). Four subfractions IV-1, IV-2, IV-3 and IV-4 were obtained and analyzed for glucosamine, galactosamine, uronic acid and sulfate (tab. 1). In none of the subfractions could keratan sulfate be completely separated from chondroitin sulfate and dermatan sulfate, though the keratan sulfate content was lowèst in subfraction IV-1 (28\%) and highest in IV-3 (55\%) as shown by the glucosamine/galactosamine ratio (tab. 1). In all fractions the glucosamine content corresponded well with the galactose content, and the galactosamine content corresponded well with the uronic acid content. All fractions were oversulfated as shown by the sulfate/ hexosamine ratio.
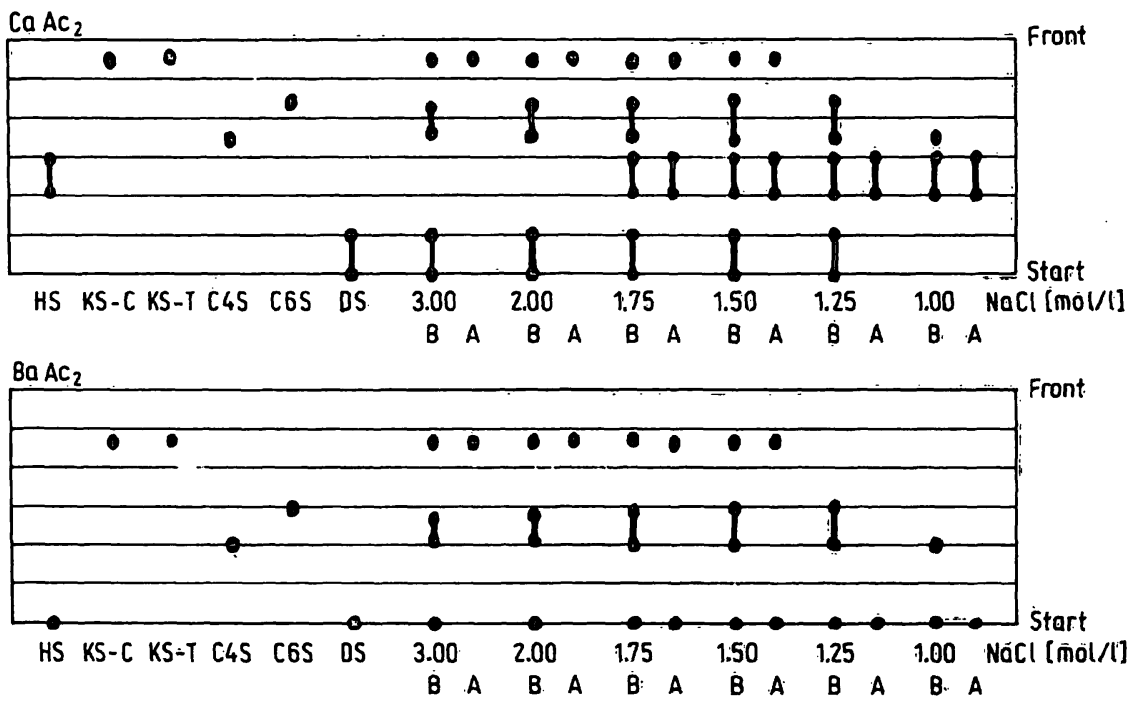

Fig. 1. TLC chromatography according to 1.c. (16) of the aortic glycosaminoglycans eluted by different $\mathrm{NaCl}$ concentrations from Dowex $1 \times 2$ columns in the calcium acetate/ethanol system $\left(\mathrm{Ca} \mathrm{Ac}_{2}\right)$ and barium acetate/ethanol system $\left(\mathrm{Ba} A c_{2}\right)$ before $(\mathrm{B})$ and after (A) digestion with chondroitin ABC-lyase. HS = heparan sulfate (human liver); $\mathrm{KS}-\bar{C}=$ keratan sulfate (bovine cornea); KS-T = keratan sulfate (bovine tracheal cartilage); $\quad \mathrm{C} 4 \mathrm{~S}=$ chondroitin 4-sulfate (bovine trachedl cartilage); C6S = chondroitin 6-sulfate (bovine tracheal cartilage); DS = dermatan sulfate (porcine skin). 


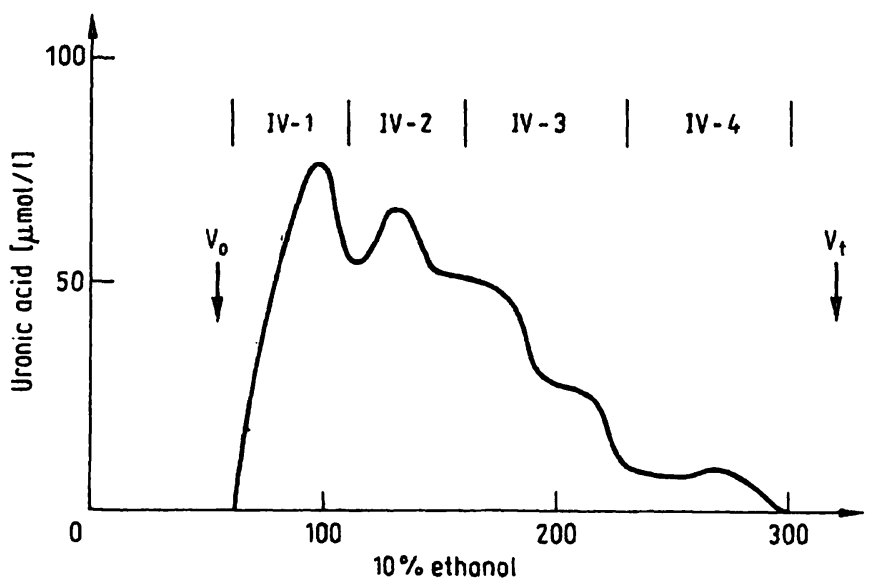

Fig. 2. Sephadex G-100 chromatography of the keratan sulfatecontaining Dowex $1 \times 2$ fraction eluted with $3 \mathrm{~mol} / 1$ $\mathrm{NaCl}$ from aortae of the 8th decade (69-76 years). Further details in material and methods. Analyses of the subfraction IV-1, IV-2, IV-3 and IV-4 are listed in table 1 .

Tab. 1. Analytical data [ $\mu \mathrm{mol} /$ fraction] of fraction IV and its subfractions from age-group $69-76$ years. The four subfractions were obtained by chromatography of fraction IV on Sephadex G-100 eluted with $100 \mathrm{ml} / \mathrm{l}$ ethanol.

\begin{tabular}{lcllll}
\hline & IV & IV-1 & IV-2 & IV-3 & IV-4 \\
\hline Glucosamine & 5.7 & 0.75 & 2.7 & 2.1 & 0.19 \\
Galactose & 6.1 & 0.70 & 2.7 & 2.4 & 0.30 \\
Galactosamine & 7.3 & 2.0 & 3.4 & 1.7 & 0.16 \\
Uronic acid & 7.1 & 2.1 & 3.2 & 1.7 & 0.12 \\
Sulfate & 19.3 & 4.0 & 9.7 & 5.1 & 0.51 \\
Glucosamine & 0.78 & 0.37 & 0.79 & 1.24 & 1.19 \\
Galactosamine & & & & & \\
Sulfate & 1.49 & 1.45 & 1.58 & 1.35 & 1.34 \\
Hexosamine & & & & & \\
\hline
\end{tabular}

\section{Age-dependent distribution of the glycosaminoglycans in the human aorta}

The age-related decrease in glycosaminoglycan content of the human aorta (tab. 2) from 18.2 in the 2 nd decade to $14.2 \mu \mathrm{mol}$ hexosamine per $\mathrm{g}$ dry weight in the 8th decade does not seem very pronounced, though one must keep in mind that the content of inorganic materials. was not included in the dry weights. These inorganic residues, which were shown by infrared analyses to be predominantly calcium phosphate, amounted to less than $1 \%$ in the 2 nd decade, nearly $9 \%$ in the 4 th, about

Täb. 2. Total glycosaminoglycan content and its distribution in Dowex fractions II, III and IV (eluted with $0.5,1.5$ and $3.0 \mathrm{~mol} / \mathrm{i} \mathrm{NaCl}$ resp.) from human aortae of different age given by their hexosamine values [ $\mu \mathrm{mol} / \mathrm{g}$ dry weight].

\begin{tabular}{lllll}
\hline $\begin{array}{l}\text { Age group } \\
\text { (a) }\end{array}$ & $\begin{array}{l}\text { Total } \\
\text { hexosamine }\end{array}$ & \multicolumn{4}{l}{$\begin{array}{l}\text { Total hexosamine } \\
\text { in fractions }\end{array}$} \\
& & II & III & IV \\
\hline 13 & 18.2 & 1.8 & 13.0 & 3.4 \\
$31-38$ & 15.3 & 2.1 & 10.2 & 3.0 \\
$52-59$ & 15.1 & 1.0 & 11.5 & 2.6 \\
$69-76$ & 14.2 & 2.5 & 9.1 & 2.6 \\
\hline
\end{tabular}

$11 \%$ in the 6 th and more than $14 \%$ in the 8 th decade of age. With regard to the aortic segments, the highest values for inorganic residues were found in the region of the bifurcatio aortae, e.g. $25 \%$ in segment $\mathrm{C}$ of the 8 th decade.

The decrease in total hexosamine content with age is also found in fractions III and IV (tab. 2), in which the chondroitin sulfates, dermatan sulfate, heparan sulfate and keratan sulfate appeared.

Table 3 shows especially the situation in fractions IV, where the content of the galactosaminoglycans decreases continuously with age, and the keratan sulfate concentration remains constant up to the sixth decade before increasing up to the 8 th decade by $50 \%$. The degree of sulfatation, expressed as sulfate/hexosamine ratio, behaves in a similar manner (tab. 3). Glucosamine/ galactose and galactosamine/uronic acid ratios are near to unity in fractions IV of all age-groups.

The concentrations and relative proportions of the different glycosaminoglycan types in the aortae between the 2nd and 8th decade of age are shown in table 4. The main fractions are represented by chondroitin 4-sulfate

Tab. 3. Analytical data $[\mu \mathrm{mol} / \mathrm{g}$ dry weight] of the glycosaminoglycans from human aortae of different age groups in fractions IV eluted from Dowex $1 \times 2$ columns with $3 \mathrm{~mol} / 1 \mathrm{NaCl}$.

Glucosamine, galactosamine, uronic acid and sulfate were estimated as described in methods.

\begin{tabular}{lllll}
\hline & \multicolumn{2}{l}{ Age group } & & \\
& $13 \mathrm{a}$ & $31-38 \mathrm{a}$ & $52-59 \mathrm{a}$ & $69-76 \mathrm{a}$ \\
\hline Glucosamine & 0.8 & 0.7 & 0.8 & 1.2 \\
Galactosamine & 2.6 & 2.3 & 1.8 & 1.4 \\
Uronic acid & 2.4 & 2.1 & 1.7 & 1.5 \\
Galactose & 0.9 & 0.9 & 1.0 & 1.3 \\
Sulfate & 4.5 & 3.8 & 3.5 & 4.0 \\
Sulfate & & & & \\
Hexosamine & 1.30 & 1.29 & 1.35 & 1.49 \\
\hline
\end{tabular}

Tab. 4. Distribution of the different glycosaminoglycans from human aortae of different age. Data given in $\mu \mathrm{mol} / \mathrm{g}$ dry weight. Data in brackets: $\mathrm{mol} / 100 \mathrm{~mol}$ of total glycosaminoglycans.

$\mathrm{Ch}$ = very low sulfated chondroitin sulfate;

$\mathrm{C} 4 \mathrm{~S}=$ chondroitin 4-sulfate;

$\mathrm{C6S}=$ chondroitin 6-sulfate;

DS = dermatan sulfate;

HS = heparan sulfate;

KS = keratan sulfate;

$\mathbf{H A}=$ hyaluronate

\begin{tabular}{lllllllll}
\hline & \multicolumn{3}{l}{ Age group } & & & & \\
& $13 a$ & \multicolumn{2}{l}{$31-38 \mathrm{a}$} & \multicolumn{2}{l}{$52-59 \mathrm{a}$} & \multicolumn{2}{l}{$69-76 \mathrm{a}$} \\
\hline Ch & 0 & $(0)$ & 0.3 & $(2.0)$ & 0.2 & $(1.3)$ & 0.4 & $(2.8)$ \\
C4S & 3.8 & $(20.9)$ & 3.1 & $(20.3)$ & 4.6 & $(30.5)$ & 3.0 & $(21.1)$ \\
C6S & 4.6 & $(25.3)$ & 4.4 & $(28.7)$ & 3.1 & $(20.5)$ & 3.0 & $(21.2)$ \\
DS & 2.3 & $(12.6)$ & 2.0 & $(13.1)$ & 2.6 & $(17.2)$ & 1.9 & $(13.4)$ \\
HS & 4.9 & $(26.9)$ & 3.1 & $(20.3)$ & 3.0 & $(19.9)$ & 2.6 & $(18.3)$ \\
KS & 0.8 & $(4.4)$ & 0.7 & $(4.6)$ & 0.8 & $(5.3)$ & 1.2 & $(8.4)$ \\
HA & 1.8 & $(9.9)$ & 1.7 & $(11.0)$ & 0.8 & $(5.3)$ & 2.1 & $(14.8)$ \\
\hline
\end{tabular}


(20-30\%) chondroitin 6-sulfate (20-29\%) and heparan sulfate $(18-27 \%)$ in these age-groups, followed by dermatan sulfate $(13-17 \%)$, hyaluronate $(5-15 \%)$ and keratan sulfate (4-8\%). The fraction named chondroitin is a very low sulfated chondroitin sulfate eluted in fraction Il together with hyaluronate. It accounts for $1-3 \%$ of the total glycosaminoglycans and was digested by chondroitin AC- and ABC-lyases. Enzymatic degradation of fractions III and IV by chondroitin AC- and ABC-lyase showed that only traces of 2-acetamido-2-deoxy-3-0( $\beta$ - $D$-gluco-4-enpyranosyluronsäure)- $D$-galactose were liberated from chondroitin 4-sulfate, chondroitin 6sulfate and dermatan sulfate. These results match the high degree of sulfatation found in fractions IV from the different age-groups (tab. 3).

The concentration of chondroitin 6-sulfate decreases from the 2 nd to the 8 th decade, whereas the contents of chondroitin 4-sulfate and dermatan sulfate show no tendency to increase or decrease. The relative proportion of chondroitin 6-sulfate seems to be diminished between the 4th and 6th decade (tab. 4). A similar decrease in the relative proportion of heparan sulfate is found between the 2 nd and the 4 th decade. The keratan sulfate concentration increases between the two last age-groups, but the percentage of keratan sulfate shows a tendency to increase in all age-groups, the increase being only $20 \%$ from the 2 nd to the 6th decade, and nearly $60 \%$ from the 6 th to the 8 th decade (tab. 4).

\section{Topographic changes of the glycosaminoglycan distribu= tion along the aortae with age}

Since results of the longitudinal distribution of the glycosaminoglycans in human aortae of different age are incomplete, we tried to obtain further data from three aortic segments of similar size: the aortic arch (segment A), the region at the origin of the arteriae renales (segment B) and the bifurcatio aortae (segment C), with regard to the 4th and the 8th decade of age. As can be seen from table 5 , the total glycosaminoglycan concentration of the younger group increases from proximal to distal regions especially from segment $A$ to $B$, whereas in the older group the total glycosaminoglycan concentration remains nearly constant in all segments, being lower in $\mathrm{B}$ and $\mathrm{C}$, and higher in $\mathrm{A}$ than the corresponding ones of the younger aorta. The glucosaminoglycans showed their highest concentration in the region of the bifurcatio $(\mathrm{C})$ in both age groups, and the galactosaminoglycan contents decreased in the two distal segments with age.

The concentration of hyaluronate increases from proximal to distal in both age groups especially in the older. The relative proportion of hyaluronate to total glycosaminoglycan seems to remain constant along the aorta in the younger age-group, but to increase significantly in the older. During ageing, the content of hyaluronate as well as its relative proportion decrease in segment $\mathbf{A}$ and increase in segment $C$.
Tab. 5. Topographic distribution [ $\mu \mathrm{mol} / \mathrm{g}$ dry weight] of the gly cosaminogly cans from aortae of different age. Data in brackets: $\mathrm{mol} / 100 \mathrm{~mol}$ of total glycosaminoglycans in the aortic segment.

$A=$ arcus aortae

$B=$ aorta at the origin of the arteriae renales C = bifurcatio aortae

\begin{tabular}{llll}
\multicolumn{1}{l}{} & $\begin{array}{l}\text { Topo- } \\
\text { graphic } \\
\text { segment }\end{array}$ & $\begin{array}{l}\text { Age group } \\
31-38 \mathrm{a}\end{array}$ & $69-76 \mathrm{a}$ \\
& A & $1.2(10.8)$ & $0.6(4.6)$ \\
& B & $1.8(10.6)$ & $1.4(9.9)$ \\
Hyaluronate & C & $2.0(11.2)$ & $4.3(29.5)$ \\
& A & $1.4(12.6)$ & $3.5(25.3)$ \\
Heparan sulfate & B & $3.3(19.4)$ & $2.4(16.8)$ \\
& C & $4.7(26.3)$ & $2.0(13.8)$ \\
Keratan sulfate & A & $0.5(4.5)$ & $0.8(6.0)$ \\
& B & $0.7(4.1)$ & $1.0(7.4)$ \\
Dermatan sulfate & C & $1.0(5.6)$ & $1.6(10.9)$ \\
& A & $1.9(17.1)$ & $1.7(12.2)$ \\
& B & $2.7(15.9)$ & $2.1(15.0)$ \\
Chondioitin 4-sulfate & C & $1.6(8.9)$ & $1.9(13.1)$ \\
& A & $3.1(27.9)$ & $2.4(17.6)$ \\
& B & $3.0(17.6)$ & $4.6(32.9)$ \\
Chondroitin 6-sulfate & A & $3.3(18.4)$ & $2.4(16.7)$ \\
& B & $3.0(27.1)$ & $4.8(34.3)$ \\
& C & $5.5(32.4)$ & $2.5(18.0)$ \\
& & & $2.3(16.0)$ \\
\hline
\end{tabular}

While heparan sulfate, expressed as $\mu \mathrm{mol} / \mathrm{g}$ dry weight and $\mathrm{mol} / 100 \mathrm{~mol}$ total glycosaminoglycan, increases from the aortic arch to the bifurcatio in the younger aorta, the reverse is the case in the older aorta. This means, with regard to ageing, that the heparan sulfate increases in the region of the arcus aortae, while decreasing in the middle region and even more so in the region of the bifurcatio.

The keratan sulfate content ( $\mu \mathrm{mol} / \mathrm{g}$ dry weight) increases from proximal to distal by $100 \%$ in the younger and the older aorta. This increase is less pronounced in terms of its relative proportion ( $\mathrm{mol} / 100 \mathrm{~mol}$ total glycosaminoglycan) especially in the younger aorta. An age-related increase in the concentration $(\mu \mathrm{mol} / \mathrm{g}$ dry weight) and the relative proportion (mol/100 mol total glycosaminoglycan) of keratan sulfate can be observed in all segments of the aorta.

Dermatan sulfate does not show pronounced differences in its concentration and relative proportion along the aorta. With age there seems to be a decrease in the region of the aortic arch and perhaps in the middle segment, and an increase in the region of the bifurcatio.

The ratio of the two chondroitin sulfates is nearly unity in the region of the aortic arch from the younger group, but in the older this ratio is shifted in favour of chondroitin 6-sulfate. The latter situation is also found in segments $B$ and $C$ of the younger group, the reverse being the case in segment $B$ of the older group, whereas the chondroitin 4-sulfate/chondroitin 6-sulfate ratio is nearly unity in the region of the bifurcatio. 
In summarizing the changes of the different glycosaminoglycan types in the three aortic segments, it can be established that in the region of the aortic arch (segment A) the concentration ( $\mu \mathrm{mol} / \mathrm{g}$ dry weight) and the relative proportion (mol/100 mol total glycosaminoglycan) of hyaluronate, dermatan sulfate and chondroitin 4-sulfate decrease on ageing, whereas those of heparan sulfate, keratan sulfate and chondroitin 6-sulfate exhibit an age-related increase. In the region at the origin of the arteriae renales (segment B), only keratan sulfate and chondroitin sulfate show an increase in content and relative proportion with age, while the other glycosaminoglycans decrease. The concentrations $(\mu \mathrm{mol} / \mathrm{g}$ dry weight) and relative proportions ( $\mathrm{mol} / 100 \mathrm{~mol}$ total glycosaminoglycan) of hyaluronate, keratan sulfate and dermatan sulfate in the region of the bifurcatio aortae increase during ageing, whereas those of heparan sulfate and the chondroitin sulfates decrease. These changes are most pronounced for hyaluronate, keratan sulfate, heparan sulfate and chondroitin 6-sulfate, especially in the aortic segment with the highest deposition of inorganic material.

\section{Discussion}

According to our results the total glycosaminoglycan content of the intimal plus medial layer of human aortae decreases with increasing age. This finding is in agreement with that of Clausen (7) who stated a decrease of the uronic acid content of the aorta on ageing, whereas Krüger \& Teller (8) found an increase of this glycosaminoglycan constituent. With regard to our results one must consider that the decrease of the total glycosaminoglycan content between the 2nd $(18.2 \mu \mathrm{mol}$ hexosamine per g dry weight) and the 8th decade $(14.2 \mu \mathrm{mol} / \mathrm{g}$ dry weight) becomes more distinct when the mineral residues are included in the dry weights; in this case there would be a decrease from 18.0 to $12.4 \mu \mathrm{mol} / \mathrm{g}$ dry weight. The residues were shown by infrared analysis to consist nearly completely of calcium phosphate. Their contents increase from the aortic arch (segment $A$ ) to the bifurcatio aortae (segment $C$ ) in each age group. Possibly, this may be an expression of the number of atherosclerotic lesions, an increase of which in the abdominal aorta was found by Montani et al. (17). Thus, the mineral residues in the aorta of the 8 th decade which average $14 \%$ of dry weight, reach about $25 \%$ in the region of the bifurcatio.

The relative proportions of the different aortic glycosaminoglycan types in all age groups amount to $20-30 \%$ chondroitin 4-sulfate, $20-29 \%$ chondroitin 6-sulfate, 18-27\% heparan sulfate, 13-17\% dermatan sulfate, $5-15 \%$ hyaluronate, $4-8 \%$ keratan sulfate and $1-3 \%$ chondroitin. The fraction named chondroitin is an extremely low sulfated chondroitin sulfate which could be degraded by chondroitin $\mathrm{AC}$ - and $\mathrm{ABC}$-lyase. The enzymic degradation of the fractions containing the chondroitin sulfates and dermatan sulfate by chondroitin $\mathrm{AC}$ - and $\mathrm{ABC}$-lyase resulted in only traces of unsulfated and unsaturated disaccharides. This agrees with the high sulfate contents of the glycosaminoglycans, especially those in fraction IV, the sulfatation degree of which was found to be between 1.3 and 1.5.

In the total aorta the content of chondroitin 6-sulfate seems to decrease from the 2 nd to the 8 th decade, whereas the concentrations of chondroitin 4-sulfate and dermatan sulfate show no tendency to decrease or increase. Recently, Toledo \& Mourao (9) found in the intimal + medial layer of human aortae chondroitin 6-sulfate/chondroitin 4-sulfate-ratios of 2-3 independent of age; in atheromata these ratios were as high as 4-6. We are not able to confirm their results, as we found chondroitin 6-sulfate/chondroitin 4-sulfate-ratios of only 1.2 in the 2nd, 1.4 in the 4th, 0.7 in the 6th and 1.0 in the 8 th decade of age. Assuming that the number of atherosclerotic lesions in the human aortae studied by us increase on ageing, the chondroitin 6-sulfate/chondroitin 4-sulfate-ratios would have to increase with age to values above 2 according to Toledo \& Mourao (9). This, however, is not the case; rather we found a decrease of the ratio with age. Thus, our results do not support the suggestion of Toledo \& Mourao (9) that a relative increase of chondroitin 6-sulfate in human aortic tissue of adults and in atherosclerosis reflects structural and metabolic modifications, which - as chondroitin 4-sulfate, but not chondroitin 6-sulfate, is capable of inhibiting the formation of complexes between LDL and highly sulfated glycosaminoglycans (28) - favour the deposition and accumulation of lipoproteins within the connective tissue framework of the aortic wall.

Investigation of the topographic distribution of the different glycosaminoglycan types along the aorta of the 4th and 8th decade, provides more detailed information. In the younger aorta the chondroitin 6-sulfate/ chondroitin 4-sulfate ratio increases from 1 in the aortic arch to nearly 2 in both the following segments (tab. 5), whereas in the older aorta this ratio decreases from about 2 in the aortic arch to less than 1 in segment $B$ and to 1 in segment $C$. In the same direction from proximal to distal in the older aorta there is a decrease in the proportion of chondroitin 6-sulfate, whereas in the younger aorta chondroitin 6-sulfate remains nearly constant in all three segments. On ageing the relative proportion of chondroitin 6-sulfate increases in the aortic arch, but decreases in both the other segments. The proportion of chondroitin 4-sulfate does not seem to change in the bifurcatio, but it increases in segment $B$ and decreases in the aortic arch.

Dermatan sulfate does not exhibit significant changes with age in the total aorta, as also reported by Toledo \& Mourao (9). In the region of the bifurcatio, however, where most of the mineral residues and possibly most 
of the atherosclerotic lesions are located, we detected a significant increase in the proportion of dermatan sulfate. Interactions between plasma LDL and VLDL and extracellular proteochondroitin-dermatan sulfate (29), which was also shown to induce a moderate release of lipoprotein lipase in human aorta (30), has been implicated in the trapping of these lipoproteins in the aortic arterial wall and in the subsequent development of atherosclerotic lesions. This hypothesis has been supported by the isolation of intact lipoprotein-glycosaminoglycan complexes from human atherosclerotic lesions (31) as well as from lesions from experimental animals (32). Recently Salisbury \& Wagner (33) found in human aortae a high molecular weight proteoglycan population which was free of dermatan sulfate and capable of associations with hyaluronate, and a second proteoglycan population of lower molecular weight and high dermatan sulfate content which did not aggregate with hyaluronate. From bovine aortae Kapoor et al. (34) isolated 3 proteoglycan populations, one of which containing only chondroitin 6-sulfate chains, the other two being proteodermatan sulfates of different composition. It is tempting to speculate from our results that with increasing age the proportion of the aortic proteoglycans in segment $C$ (tab. 5) might change, in the sense that the chondroitin 6-sulfate-containing proteoglycan population capable of forming aggregates with hyaluronate is partly substituted by dermatan sulfate-containing proteoglycans, whereby the possibility of complexing with plasma LDL and VLDL might increase.

The possible uptake of plasma LDL and VLDL complexing with extracellular aortic proteoglycans might be supported by our finding that the proportion of heparan sulfate decreases significantly in segment $C$ on ageing (tab. 5). This could mean a loss in the protective function of the heparan sulfate at the endothelial surface and may thereby facilitate the trapping of the lipoproteins by extracellular intimal proteoglycans.

From the distribution of hyaluronate and keratan sulfate further perspectives can be derived. The proportion of hyaluronate is decreased with age in the aortic arch and increased strongly in the bifurcatio aortae. With respect to the formation of aortic proteoglycan aggregates, the existence of which and their similarity to those of cartilage have been demonstrated by several groups $(33,35,36,37)$, the behavior of the hyaluronate concentration on ageing could suggest a decrease in the aortic arch and an increase in the bifurcatio aortae. An increase in hyaluronate does not necesșarily mean an increase in aggregation, since aortic proteoglycans seem

\section{References}

1. Schwarz, W. (1954) Virchows Arch. Path. Anat. 324, 612621.

2. Kaplan, D. \& Meyer, K. (1960) Proc. Soc. Exp. Biol. Med. $105,78-81$. to exhibit a particularly low aggregation rate (33). Therefore, it might even be possible, that the hyaluronate content increases as a sort of compensatory effect for losses in e.g. water-binding etc, while the content of proteoglycan aggregates decreases.

The relative proportion, but also the' concentration of keratan sulfate, which was for the first time isolated and characterized by us several years ago (10-12), exhibit an increase from proximal to distal (from segment $\mathbf{A}$ to C) and also in each segment on ageing. Montani et al. (17) reported an increase of keratan sulfate in the abdominal aorta, but no change in the aortic arch. However, the methods employed by these authors, especially to determine keratan sulfate, did not seem to be suitable for obtaining exact resultss. Increassing concentrations and relative proportions of keratan sulfate might point to an increase of the so-called keratan sulfate-rich region in the aortic proteoglycans, though the presence of keratan sulfate in aortic proteoglycans together with chondroitin sulfates has not yet been shown. But, since their similarity to cartilaginous proteoglycans was demonstrated $(33,35,36,37)$, it seems plausible to ask if the changing composition of the aortic proteoglycans with age resembles that of the cartilaginous proteoglycans on ageing. Inerot et al. (38) were able to demonstrate that the relative proportion of keratan sulfate increases with a corresponding decrease in the proportion of the chondroitin sulfates in old hip cartilage, this being a reason for the decreasing elasticity with age. As the elasticity of the older aorta decreases, it seems obvious that the composition of the aortic proteoglycan might be changed in an analogous manner: the keratan sulfate content increases at the expense of the chondroitin 6-sulfate or chondroitin 4-sulfate content (sée table 5).

Since the increasing deposition of calcium phosphate in each aortic segment correlates with the increasing concentration and relative proportion of keratan sulfate, both spatially in moving from the aortic arch to the bifurcatio aortae, and with age, a sört of nucleating function may also be considered for keratan sulfate. As ion exchanging macromolecules the glycosaminoglycans exhibit different affinities to $\mathrm{Ca}^{2+}$ (39) which is high in chondroitin sulfates, eșpecially chondroitin 6-sulfate, and lowest in keratan sulfáte. A decrease in chondroitin sulfate content of the aortic proteoglycans in favour of keratan sulfate, which binds $\mathrm{Ca}^{2+}$ to a much lesser extent, would increase the portion of de-immobilized $\mathrm{Ca}^{2+}$, which may give rise to insoluble calcium phosphate. Such a micro-precipitate could then serve. as a crystallization nucleus.
3. Böttcher, J. F. \& Klynstra, F. B. (1962) Atheroscler. Res. -2, 263-269.

4. Bertelsen, S. \& Jensen, C. E. (1960) Acta Pharmacol. Toxicol. $16,250-259$. 


\begin{tabular}{|l|l}
\hline W & Walter de Gruyter \\
Oag & Berlin-New York
\end{tabular}

\section{T. C. Bøg-Hansen}

(Editor)

\section{T. C. Bøg-Hansen} (Editor)

\section{P. Brätter \\ P. Schramel}

(Éditors)
P. Schramel

P. Brätter

(Editors)

\section{Lectins}

\section{Biology, Biochemistry, \\ Clinical Biochemistry \\ Volume 1}

Proceedings of the Third Lectin Meeting, Copenhagen, June 1980 1981. $17 \mathrm{~cm} \times 24 \mathrm{~cm}$. XII, 418 pages with figures and tables. Hardcover. DM 120,-; approx. US \$60.00 ISBN $311008483 X$

Contents (Main chapters)

Part I. Lectins: Distribution, Isolation, Characterization, and

Function

Part II. Methods Based on Reactions of Lectins

Part III. Glycoproteins Studied by Reaction with Lectins

\section{Lectins}

\section{Biology, Biochemistry, Clinical Biochemistry Volume 2}

Proceedings of the Fourth Lectin Meeting, Copenhagen, June 8-12, 1981

1982. $17 \mathrm{~cm} \times 24 \mathrm{~cm}$. Approx. 810 pages. Numerous figures and tables. Hardcover. In press. ISBN 3110086808

\section{Trace Element \\ Analytical Chemistry in Medicine and Biology}

Proceedings of the First International Workshop Neuherberg, Federal Republic of Germany, April 1980

$1980.17 \mathrm{~cm} \times 24 \mathrm{~cm}$. XV, 851 pages. Numerous illustrations. Hardcover. DM 180,-; approx. US \$90.00 ISBN 3110083574

The main objective of the meeting was to stimulate at an international level the exchange of views between the analytical specialists and the users of analytical data with regard to the bioniedical application of trace element research.

\section{Trace Element Analytical Chemistry in Medicine and Biology}

Proceedings of the Second International Workshop Neuherberg, Federal Republic of Germany, April 1982 In preparation. 


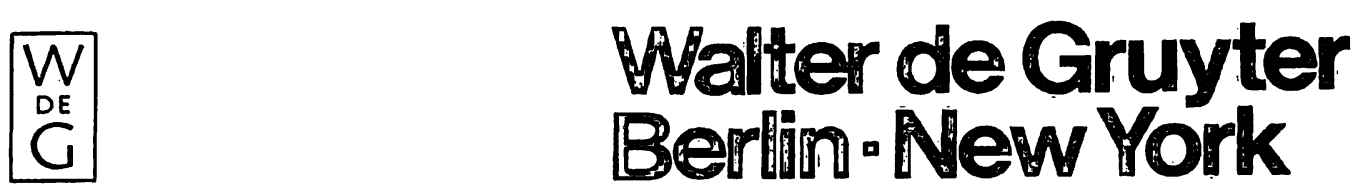

D. Brandenburg

A. Wollmer

(Editors)

\section{K. Keck \\ P. Erb \\ (Editors)}

Insulin

Chemistry, Structure and

Function of Insulin

and Related Hornones

Proceedings of the Second International Insulin Symposium, Aachen, Germany, September 4-7, 1979

$1980.17 \mathrm{~cm} \times 24 \mathrm{~cm} .752$ pages. Numerous figures.

Hardcover. DM 170,-; approx. US \$85.00

ISBN 3110081563

These proceedings of the Insulin Symposium present the current state of knowledge and research in the field of Insulin. The problems are presented and discussed from various standpoints (chemistry, biochemistry, bịology, crystallography, immunology and medicine).

Contents: Introduction

Sections I-XI

Structure of Insulin - Peptide Synthesis - Semisynthesis and Chemical Modification - Radioactive Labelling and Separation Techniques - Receptors and Hormone-Receptor Interaction . Photo-Induced Hormone-Receptor Coupling - Structure, Binding, Activity - Degradation - Immunology - Biosynthesis, Storage, Evolution - Insulin-Related Hormones.

Abbreviations - Subject Index · Author Index.

\section{Basic and Clinical Aspects of Immunity to Insulin \\ Proceedings. International Workshop, September 28-October 1, 1980, Konstanz, Germany}

1981. $17 \mathrm{~cm} \times 24 \mathrm{~cm}$. XIV, 442 pages. Numerous illustrations. Hardcover. DM 140,-; approx. US $\$ 70.00$ ISBN 3110084406

In order to integrate the large quantities of information available regarding the chemistry and immunology of insulin as well as the clinical aspects of diabetes and its control, it is necessary to establish interdisciplinary lines of communication between specialists in these various fields. It was the intention of a Symposium held in Konstanz, FRG, from September 28 to October 1,1980, to bring together cliniciäns, immunólogists and chemists active in insulin research, to provide an open forum to exchange ideas and experience, to establish contacts and to intensify cooperation between these groups. 
5. Bertelsen, S. \& Marcker, K. (1961) Acta Pharmacol. Toxicol. 18, 1-9.

6. Buddecke, E. (1960) Hoppe-Seyler's Z. Physiol. Chem. 318, 33-55.

7. Clausen, B. (1963) Lab. Invest. 12, 538-544.

8. Krüger, C. \& Teller, W. M. (1975) Z. Kinderheilkunde 119 , 253-259.

9. Toledo, O. M. S. \& Mourao, P. A. S. (1979) Biochem. Biophys. Res. Commun. 89, 50-55.

10. Stuhlsatz, H. W., Löffler, H. \& Greiling, H. (1976) Arch. Int. Physiol. Biochem. 84, XIV.

11. Greiling, H., Gressner, A. M. \& Stuhlsatz, H. W. (1977) in: Experimental models of chronic inflammatory disease (Glynn, L. E. \& Schlumberger, H. D., eds.) pp. 406-420, Springer-Verlag, Berlin-Heidelberg-New York.

12. Stuhlsatz, H. W., Löffler, H. \& Greiling, H. (1978) Fresenius Z. Anal. Chem. 290, 149-150.

13. Murata, K., Nakazawa, K. \& Hamai, A. (1975) Atherosclerosis $21,93-193$.

14. Manley, G. \& Hawksworth, J. (1965) Nature 206, 11521153.

15. Montani, A., Mainardi, E., Cantu, E., Magrini, U. \& Castellani, A. A. (1977) It. J. Biochem. 26, 88.

16. Montani, A., Magrini, U. \& Castellani, A. A. (1977) Int. Conf. on Atherosclerosis, Milano, Abstr. p. 51.

17. Montani, A., Roggi, C., Zocchi, G., Magrini, U. \& Castellani, A. A. (1979) in: Clin. Enz. Symp. 2 (Burlina, A. \& Galzigna, L., eds.) pp. 197-208, Piccin Medical Books, Padua.

18. Humbel, R. \& Chamoles, N. A. (1972) Clin. Chim. Acta 40, $290-293$.

19. Greiling, H. (1974) in: Methoden der enzymatischen Analyse (Bergmeyer, H. U., ed.), Vol. 2, 3rd ed., pp. 1202-1209, Verlag Chemie, Weinheim.

20. Greiling, H. \& Eberhard, A. (1974) in: Methoden der enzymatischen Analyse (Bergmeyer, H. U., ed.) Vol. 2, 3rd ed., pp. 1210-1216, Verlag Chemie, Weinheim.

21. Lagunoff, D., Pritzl, P. \& Scott, C. R. (1967) Proc. Soc. Exper. Biol. Med. 126, 34-38.
22. Dische, Z. (1947) J. Biol. Chem. 167, 189-198.

23. Bitter, T. \& Muir, H. (1962) Anal. Biochem. 4, 330-334.

24. Stuhlsatz, H. W., unpublished.

25. Kurz, G. \& Wallenfels, K. (1974) in: Methoden der enzymatischen Analyse, Vol. 2, 3 rd ed. (Bergmeyer, H. U., ed.) pp. 1324-1327, Verlag Chemie, Weinheim.

26. Greiling, H., Herbertz, T. \& Stuhlsatz, H. W. (1964) HoppeSelyler's Z. Physiol. Chem. 336, 149-162.

27. Greiling, H., Stuhlsatz, H. W., Cantz, M. \& Gehler, J. (1978) J. Clin. Chem. Clin. Biochem. 16, 329-334.

28. Nakashima, Y., DiFerrante, N., Jackson, R. L. \& Pownall, H. J. (1975) J. Biol. Chem. 250, 5386-5392.

29. Vijayagopal, P., Srinivasan, S. R., Radhakrishnamurthy, B. \& Berenson, G. S. (1981) J. Biol. Chem. 256, 8234-8241.

30. Vijayagopal, P., Radhakrishnamurthy, B., Srinivasan, S. R. \& Berenson, G. S. (1980) Lab. Invest. 42, 190-196.

31. Srinivasan, S. R., Dolan, P., Radhakrishnamurthy, B., Pargaonkar, P. S. \& Berenson, G. S. (1975) Biochim. Biophys. Acta 388, 58-70.

32. Mawhinney, T. P., Augustyn, J. M. \& Fritz, K. E. (1978) Atherosclerosis 31, 155-167.

33. Salisbury, B. G. S. \& Wagner, W. D. (1981) J. Biol. Chem. $256,8050-8057$.

34. Kapoor, R., Phclps, C. F., Cöster, L. \& Fransson, L.-A. (1981) Biochem. J. 197, 259-268.

35. Eisenstein, R., Larsson, S.-E., Kuettner, K. E., Sorgente, N. \& Hascall, V. C. (1975) Atherosclerosis 22, 1-17.

36. Oegema, T. R., Jr., Hascall, V. C. \& Eisenstein, R. (1979) J. Biol. Chem. 254, 1312-1318.

37. Gardell, S., Baker, J., Caterson, B., Heinegard, D. \& Roden, L. (1980) Biochem. Biophys. Res. Commun. 95, 18231831.

38. Inerot, S., Heinegard, D., Audell, L. \& Olsson, S.-E. (1978) Biochem. J. 169, 143-156.

39. Lippman, M. (1964) Trans. N. Y. Acad. Sci. 27, 342-349.

40. Vierhaus, S. (1980) Dissertation, RWTH Aachen.

PD Dr. Helmut W. Stuhlsatz

Abt. Klinische Chemie und Pathobiochemie Med. Fakultät der RWTH Aachen

Goethestr. 27/29

D-5100 Aachen 


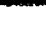

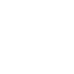

$$
\text { - }
$$

; 